\title{
Non-Penetrating Deep Sclerectomy versus Trabeculectomy in Primary Congenital Glaucoma
}

Abdelhamid Elhofi
Hany Ahmed Helaly (D)

Ophthalmology Department, Faculty of Medicine, Alexandria University, Alexandria, Egypt
Correspondence: Hany Ahmed Helaly 30 Roshdy Street, Roshdy, Alexandria, Egypt

Tel +20 I225466733

Email hany209209@yahoo.com
This article was published in the following Dove Press journal: Clinical Ophthalmology

Purpose: To evaluate the safety and efficacy of non-penetrating deep sclerectomy with a collagen implant versus trabeculectomy in primary congenital glaucoma.

Subjects and Methods: This was a retrospective interventional comparative nonrandomized clinical study that included 80 eyes of 80 children presenting with primary congenital glaucoma under the age of 3 years. Forty eyes have undergone non-penetrating deep sclerectomy (NPDS) and the other 40 eyes have undergone penetrating trabeculectomy. The main outcome measure was the reduction in intraocular pressure (IOP). Secondary outcomes included percentage of patients with complete and qualified success, need for topical antiglaucoma medications, rate of complications, and need for further interventions. Complete success of the surgical outcome was considered an IOP $\leq 16 \mathrm{mmHg}$ with no antiglaucoma medications. Qualified success was considered an IOP $\leq 16 \mathrm{mmHg}$ using antiglaucoma medications.

Results: The mean preoperative IOP was $27.4 \pm 6.9$ and $28.5 \pm 6.6 \mathrm{mmHg}$ in NPDS and trabeculectomy groups, respectively $(\mathrm{p}=0.175)$. At the end of the follow-up period, the mean IOP was $11.2 \pm 4.5$ and $11.1 \pm 3.4 \mathrm{mmHg}$ with a mean reduction of 16.2 and $17.4 \mathrm{mmHg}$ in NPDS and trabeculectomy groups, respectively. At the end of the follow-up period, ie at 36 months postoperative, the complete success rate was $60 \%$ (24 eyes) versus $57.5 \%$ ( 23 eyes), the qualified success rate was $25 \%$ (10 eyes) versus $25 \%$ ( 10 eyes), the overall success rate was $85 \%$ ( 34 eyes) versus $82.5 \%$ (33 eyes), and the rate of failure was $15 \%$ ( 6 eyes) versus $17.5 \%$ ( 7 eyes) in NPDS and trabeculectomy groups, respectively $(\mathrm{p}=0.952)$. Eight cases $(20 \%)$ of the trabeculectomy group had shallow anterior chamber. None of the NPDS group cases suffered from shallow anterior chamber.

Conclusion: Non-penetrating deep sclerectomy appears to be an efficient and safe surgical alternative to penetrating trabeculectomy in treatment of primary congenital glaucoma. Nonpenetrating deep sclerectomy has fewer postoperative complications in comparison to penetrating trabeculectomy with a comparative postoperative reduction in the intraocular pressure and overall success rates.

Trial Registration: The trial was registered on $11 / 01 / 2020$ with number PACTR202002874953456 (https://pactr.samrc.ac.za).

Keywords: deep sclerectomy, primary congenital glaucoma, non-penetrating, childhood glaucoma, non-penetrating deep sclerectomy, trabeculectomy

\section{Introduction}

One of the major causes of blindness in young children is congenital glaucoma. Its negligence can lead to drastic outcome despite its low incidence (one to ten thousand births approximately). Primary congenital glaucoma (PCG) is the isolated form not associated with other ocular or systemic anomalies. It is the most common 
form of childhood glaucoma with an incidence about one to thirty thousand births approximately. ${ }^{1,2}$ Its main pathology lies in the trabecular meshwork maldevelopment (isolated trabeculodysgenesis) that leads to increase outflow resistance to the aqueous drainage. ${ }^{3-6}$

The treatment of primary congenital glaucoma is essentially a surgical procedure. The role of topical antiglaucoma medications is only temporary before the preparation for the surgical procedure. The famous surgical interventions for PCG are goniotomy and trabeculotomy. ${ }^{7-10}$ In more advanced cases or when goniotomy and trabeculotomy are not possible, the classical option is penetrating trabeculectomy which may be done alone or in combination with trabeculotomy. Trabeculectomy has a higher success rates and less secondary interventions. However, it carries a higher rate of complications eg hypotony, choroidal detachment, cataract, bleb related infections. ${ }^{11-13}$ Glaucoma drainage devices are also used to treat PCG. ${ }^{14,15}$ The use of antimetabolites eg 5-fluorouracil and mitomycin $\mathrm{C}$ reduces scarring and increases the success rates. $^{16}$

Non-penetrating deep sclerectomy (NPDS) is another alternative where the surgeon elevates a partial thickness scleral flap and removes the external portion of Schlemm's canal together with the outer part of the trabecular meshwork including the juxtacanalicular tissue without full penetration inside the eye. This leaves a thin trabeculodescemetic membrane that plays a key role as a safety resistance to prevent excessive aqueous humor outflow. This will prevent the onset of early postoperative hypotony and its related complications, such as those encountered with trabeculectomy due to the penetrating nature of the procedure. The success of this procedure in addressing glaucoma in adults has encouraged some surgeons to perform NPDS for treating PCG in children. ${ }^{17-20}$

The aim of the current study was to evaluate the safety and efficacy of non-penetrating deep sclerectomy with a collagen implant versus trabeculectomy in primary congenital glaucoma.

\section{Subjects and Methods}

This was a retrospective interventional comparative nonrandomized clinical study that included 80 eyes of 80 children presenting with primary congenital glaucoma under the age of 3 years during the period from January 2012 to December 2016. Forty eyes have undergone nonpenetrating deep sclerectomy (NPDS group) and the other 40 eyes have undergone penetrating trabeculectomy (trab group). Records of the patients were revised and the children were recalled for a final follow up visit. The patients included had complete records covering a followup period of at least 3 years. Patients were excluded if they had secondary glaucoma ie only eyes with PCG were included, or there was a coexisting ocular pathology eg congenital cataract or a previous ocular surgery. Patients with incomplete data or follow up period were also excluded.

The current study was approved by the local ethics committee of the faculty medicine, Alexandria University, Egypt. Tenets of the Declaration of Helsinki were followed. The parents or legal caregivers of all the included children signed a written informed consent at the final follow up visit.

A complete history was taken from the parents or caregivers of the included children. This was followed by examination under inhalational anesthesia using sevoflurane (fluoromethyl hexafluoroisopropyl ether). The intraocular pressure (IOP) was measured just after the induction of the inhalational anesthesia using the hand held Perkins applanation tonometer (Haag-Streit, Harlow, UK). Complete anterior segment examination was done including assessment of the corneal diameter using a surgical caliper. If the cornea was clear enough, fundus examination was done. Then, the child was scheduled for surgery after establishing the diagnosis of PCG. Either NPDS or trabeculectomy was done. The choice between the two surgeries was done randomly using coin flip method. All the cases were operated upon by the same surgeon (A.E.) using a reproducible technique.

\section{Non-Penetrating Deep Sclerectomy Technique}

General anesthesia was used in all the cases. After a superior corneal traction suture was taken, a fornix based superior conjunctival flap was done. A rectangular $5 \times 4.5 \mathrm{~mm}$ superficial scleral flap with about one-third thickness of the sclera was created. The dissection continued until a clear cornea is reached anteriorly. This was followed by a dissection of a $4 \times 4 \mathrm{~mm}$ deeper scleral flap anteriorly to deroof Schlemm's canal and continued further anterior in the cornea to create a trabeculo-Descemet's window. This newly created deeper scleral flap was excised. The seepage of aqueous humor was noticed through the deroofed Schlemm's canal. A collagen implant Ologen (Aeon Astron Europe, Leiden, The Netherlands) was used to 
maintain the space created and to decrease the early postoperative scarring. The implant was fixed with a single 10-0 suture. It is a biodegradable collagen implant which completely degrades within $90-180$ days. $^{21-23}$ The superficial scleral flap was then sutured using 10-0 nylon sutures and the conjunctiva was sutured with 8-0 absorbable sutures. Subconjunctival injection of 5-fluorouracil was done at the end of the surgery and repeated 1 week postoperative. None of the included cases was converted to penetrating trabeculectomy.

\section{Trabeculectomy Technique}

Under general anesthesia and after a superior corneal traction suture was done, a fornix based superior conjunctival flap was created and a localized tenonectomy was done. A triangular $4 \times 4 \mathrm{~mm}$ half-thickness limbal-based scleral flap was created. The dissection continued forward for 1-2 $\mathrm{mm}$ of a clear cornea. The trabeculectomy was then completed by Kelly Descemet punch followed by peripheral iridectomy. The scleral flap was then sutured using 10-0 nylon sutures (one at the apex and one suture at each side of the triangle). The conjunctiva was closed tightly with 8-0 absorbable sutures. Subconjunctival injection of 5-fluorouracil was done at the end of the surgery and repeated 1 week postoperative.

Postoperative topical antibiotic and steroid were prescribed 5 times daily for the first month, then steroid eye drops were tapered slowly. In cases of trabeculectomy, additional topical cycloplegic eye drops (twice daily for 1 week) were added. Any complications were recorded. Also, any further intervention needed was recorded. All patients were followed up daily for the first few days to evaluate corneal haze, eye injection, anterior chamber formation, and to exclude any complications eg hyphemia, cataract, posterior synechia. Fundus examination or red reflex was done to exclude posterior segment complications eg choroidal detachment. Intraocular pressure was roughly estimated manually by gentle pressure. Then, a scheduled general anesthesia examination was conducted at 1 week, and 1, 3, 6, 9, and 12 months. Then every 6 months afterwards. More frequent visits were conducted according to individual needs. Data from the records regarding the postoperative follow up were retrieved.

The main outcome measure was the reduction in IOP. Secondary outcomes included percentage of patients with complete and qualified success, need for topical antiglaucoma medications, rate of complications, and need for further interventions. Complete success of the surgical outcome was considered an IOP $\leq 16 \mathrm{mmHg}$ with no antiglaucoma medications. Qualified success was considered an IOP $\leq 16 \mathrm{mmHg}$ using antiglaucoma medications. Failure was defined as an IOP $>16 \mathrm{mmHg}$ despite the use of medications, or if a need for another surgical glaucoma intervention was present.

Low IOP was not included in the definition of failure as many cases showed apparently very low IOP when measured under anesthesia $(0-6 \mathrm{mmHg})$. Those cases demonstrated relatively normal visual behavior regarding fixation and following, no resistance to covering the eye, and the parents described a relatively normal visual behavior during the daily activities. Besides, the effect of inhalational sevoflurane anesthesia on lowering the intraocular pressure is already well known. $^{24,25}$

Data analysis was performed using the Statistical Package for Social Sciences SPSS for Windows version 20.0 (SPSS Inc., Chicago, IL, USA). Quantitative data were described using range, mean and standard deviation. The normality of data was evaluated using the Kolmogorov-Smirnov test. ANOVA test was used to compare between different means. Independent samples $t$ test was used to compare means between both groups. Paired samples $t$ test was used for comparisons between means of the same group. Kaplan-Meier survival analysis was conducted. Chi-square test was used to compare between different percentages. Differences were considered statistically significant when the associated p-value was less than 0.05 .

\section{Results}

The current study was conducted on 80 eyes. Each of the NPDS and trabeculectomy groups included 40 eyes of 40 patients with the diagnosis of primary congenital glaucoma. The NPDS group mean age was $14.5 \pm 13.1$ months versus mean age of $13.7 \pm 12.2$ months in the trabeculectomy group. Males represented $60 \%$ in the NPDS group and $65 \%$ in the trabeculectomy group. There was no statistically significant difference between the two groups regarding the demographic data of the included patients. Table 1 shows more details about the preoperative characteristics of the included patients regarding the IOP levels, the corneal diameter, and the cup/disc ratio. Again, there was no statistically significant difference between the two groups regarding those parameters ( $p=0.175,0.422$, and 0.388 , respectively). 
Table I Characteristics of the Patients in the Non-Penetrating Deep Sclerectomy Group and the Trabeculectomy Group

\begin{tabular}{|l|l|l|l|}
\hline & Deep Sclerectomy Group $(\mathbf{n}=40)$ & Trabeculectomy Group $(\mathbf{n}=40)$ & P value* \\
\hline Age (months) & $14.5 \pm 13.1(3-36)$ & $13.7 \pm 12.2(3-35)$ & 0.521 \\
Sex (Male:Female) & $24: 16$ & $26: 14$ & 0.644 \\
Preop. IOP (mmHg) & $27.4 \pm 6.9(19.0-38.0)$ & $28.5 \pm 6.6(22.0-36.0)$ & 0.175 \\
Preop. corneal diameter (mm) & $12.5 \pm 0.7(11.5-13.0)$ & $12.6 \pm 0.7(11.5-13.0)$ & 0.422 \\
Preop. cup/disc ratio & $0.5 \pm 0.2(0.3-0.9)$ & $0.6 \pm 0.3(0.4-0.9)$ & 0.388 \\
\hline
\end{tabular}

Note: *Using independent samples $t$ test or chi-square test where appropriate.

\section{Intraocular Pressure}

The mean preoperative IOP was $27.4 \pm 6.9$ and $28.5 \pm$ $6.6 \mathrm{mmHg}$ in NPDS and trabeculectomy groups, respectively $(\mathrm{p}=0.175)$. The mean 1 week and 1 month postoperative IOP in the NPDS group was $4.3 \pm 2.8$ and $9.5 \pm$ $4.6 \mathrm{mmHg}$, respectively with a mean reduction of 23.1 and $17.9 \mathrm{mmHg}$, respectively. The mean 1 week and 1 month postoperative IOP in the trabeculectomy group was $2.1 \pm 1.2$ and $8.1 \pm 3.9 \mathrm{mmHg}$, respectively with a mean reduction of 26.4 and $20.4 \mathrm{mmHg}$, respectively. There was a statistically significant difference between the 2 groups regarding the mean IOP levels at 1 week and 1 month. At the end of the follow-up period, the mean IOP was $11.2 \pm 4.5$ and $11.1 \pm 3.4 \mathrm{mmHg}$ with a mean reduction of 16.2 and $17.4 \mathrm{mmHg}$ in NPDS and trabeculectomy groups, respectively. There was a statistically significant difference between preoperative and postoperative IOP levels along the whole follow up period for both groups $(\mathrm{p}<0.001)$. There were no statistically significant differences between the mean IOP levels of both groups starting from the $3 \mathrm{rd}$ month postoperative till the end of the follow-up period at 36 months postoperative. Using paired samples $t$ test, there was a statistically significant increase in the mean IOP level from 1 week to 1 month and from 1 month to 3 months for both groups.
Starting from the 3rd month onwards, there were no statistically significant differences along the rest of the follow-up period for both groups. Table 2 shows more details about the mean IOP levels along the different follow-up periods.

\section{Corneal Diameter and Cup/Disc Ratio}

The mean preoperative corneal diameter measured by a caliper was $12.5 \pm 0.7$ and $12.6 \pm 0.7 \mathrm{~mm}$ in NPDS and trabeculectomy groups, respectively $(\mathrm{p}=0.422)$. At the final follow up period, the mean corneal diameter was $12.6 \pm 0.7 \mathrm{~mm}$ in both groups (range from 12.0 to $13.5 \mathrm{~mm}$ ). Using ANOVA test and multiple $\mathrm{t}$ tests, there was no statistically significant difference between the two groups along the whole follow up period. The mean corneal diameter remained almost stable along the 3 years of follow up with no significant change from the preoperative levels in both groups (Table 3).

The mean preoperative cup/disc ratio was $0.4 \pm 0.2$ and $0.5 \pm 0.3$ in NPDS and trabeculectomy groups, respectively $(p=0.388)$. At the final follow up period, the mean cup/disc ratio was $0.2 \pm 0.2$ and $0.2 \pm 0.3$ in NPDS and trabeculectomy groups, respectively. There was no significant difference between the 2 groups using multiple independent samples $\mathrm{t}$ tests along different follow-up periods postoperatively.

Table 2 The Intraocular Pressure Changes Before and After Surgery in the Non-Penetrating Deep Sclerectomy Group and the Trabeculectomy Group

\begin{tabular}{|l|l|l|l|}
\hline $\begin{array}{l}\text { Intraocular Pressure } \\
\text { (mmHg) }\end{array}$ & $\begin{array}{l}\text { Deep Sclerectomy Mean } \mathbf{S ~ S D ~} \\
\text { (Range) }\end{array}$ & $\begin{array}{l}\text { Trabeculectomy Mean } \pm \text { SD } \\
\text { (Range) }\end{array}$ & P value* \\
\hline Preoperative & $27.4 \pm 6.9(19.0-38.0)$ & $28.5 \pm 6.6(22.0-36.0)$ & 0.175 \\
I week & $4.3 \pm 2.8(2.0-7.0)$ & $2.1 \pm 1.2(0.0-4.0)$ & $0.021^{* *}$ \\
I month & $9.5 \pm 4.6(4.0-17.0)$ & $8.1 \pm 3.9(4.0-12.0)$ & $0.034^{* *}$ \\
3 months & $10.9 \pm 4.3(6.0-19.0)$ & $11.3 \pm 3.1(8.0-18.0)$ & 0.121 \\
6 months & $11.3 \pm 4.5(8.0-20.0)$ & $11.5 \pm 3.9(8.0-19.0)$ & 0.254 \\
I2 months & $11.4 \pm 4.5(8.0-20.0)$ & $11.6 \pm 4.1(8.0-20.0)$ & 0.311 \\
24 months & $11.3 \pm 4.6(8.0-20.0)$ & $11.5 \pm 3.8(9.0-19.0)$ & 0.303 \\
36 months & $11.2 \pm 4.5(8.0-18.0)$ & $11.1 \pm 3.4(8.0-16.0)$ & 0.342 \\
\hline
\end{tabular}

Notes: *Using independent samples $t$ test. **Statistically significant. 
Table 3 The Mean Corneal Diameter Among the Deep Sclerectomy and Trabeculectomy Groups

\begin{tabular}{|l|l|l|l|}
\hline $\begin{array}{l}\text { Corneal Diameter } \\
(\mathbf{m m})\end{array}$ & $\begin{array}{l}\text { Deep Sclerectomy Mean } \pm \text { SD } \\
\text { (Range) }\end{array}$ & $\begin{array}{l}\text { Trabeculectomy Mean } \pm \text { SD } \\
\text { (Range) }\end{array}$ & P value* \\
\hline Preoperative & $12.5 \pm 0.7(11.5-13.0)$ & $12.6 \pm 0.7(11.5-13.0)$ & 0.422 \\
I week & $12.5 \pm 0.7(11.5-13.0)$ & $12.6 \pm 0.7(11.5-13.0)$ & 0.401 \\
I month & $12.4 \pm 0.6(11.5-13.0)$ & $12.6 \pm 0.6(11.5-13.0)$ & 0.387 \\
3 months & $12.6 \pm 0.8(12.0-13.5)$ & $12.7 \pm 0.8(11.5-13.5)$ & 0.389 \\
6 months & $12.7 \pm 0.7(12.0-13.5)$ & $12.5 \pm 0.7(11.5-13.0)$ & 0.411 \\
I2 months & $12.6 \pm 0.8(11.5-13.5)$ & $12.6 \pm 0.6(12.0-13.5)$ & 0.382 \\
24 months & $12.7 \pm 0.6(12.0-13.5)$ & $12.6 \pm 0.6(11.5-13.0)$ & 0.420 \\
36 months & $12.6 \pm 0.7(12.0-13.5)$ & $12.6 \pm 0.7(12.0-13.5)$ & 0.454 \\
\hline
\end{tabular}

Note: *Using independent samples $t$ test.

Table 4 The Mean Cup/Disc Ratio Among the Deep Sclerectomy and Trabeculectomy Groups

\begin{tabular}{|l|l|l|l|}
\hline $\begin{array}{l}\text { Cup/Disc } \\
\text { Ratio }\end{array}$ & $\begin{array}{l}\text { Deep Sclerectomy } \\
\text { Mean } \pm \text { SD } \\
\text { (Range) }\end{array}$ & $\begin{array}{l}\text { Trabeculectomy } \\
\text { Mean } \pm \text { SD } \\
\text { (Range) }\end{array}$ & P value* \\
\hline Preoperative & $0.4 \pm 0.2(0.3-0.9)$ & $0.5 \pm 0.3(0.4-0.9)$ & 0.388 \\
I week & $0.4 \pm 0.2(0.2-0.7)$ & $0.3 \pm 0.2(0.2-0.7)$ & 0.422 \\
I month & $0.3 \pm 0.1(0.1-0.6)$ & $0.3 \pm 0.1(0.2-0.7)$ & 0.399 \\
3 months & $0.3 \pm 0.2(0.1-0.5)$ & $0.3 \pm 0.2(0.1-0.6)$ & 0.378 \\
6 months & $0.3 \pm 0.2(0.1-0.5)$ & $0.2 \pm 0.2(0.1-0.6)$ & 0.422 \\
I2 months & $0.3 \pm 0.2(0.1-0.6)$ & $0.3 \pm 0.2(0.1-0.6)$ & 0.421 \\
24 months & $0.3 \pm 0.2(0.1-0.6)$ & $0.2 \pm 0.2(0.1-0.7)$ & 0.395 \\
36 months & $0.2 \pm 0.2(0.1-0.5)$ & $0.2 \pm 0.3(0.1-0.6)$ & 0.434 \\
\hline
\end{tabular}

Note: $*$ Using independent samples $t$ test.

Using paired samples $t$ tests, there was a statistically significant difference between the preoperative and the final 36 months postoperative mean cup/disc ratio (Table 4).

\section{Success and Failure Rates}

Table 5 shows the success and failure rates along the whole follow up period. At the first week, all cases showed IOP levels below $16 \mathrm{mmHg}$ with $100 \%$ complete success rate in both groups. At the end of the follow-up period ie at 36 months postoperative, the complete success rate was $60 \%$ (24 eyes) versus $57.5 \%$ ( 23 eyes), the qualified success rate was $25 \%$ (10 eyes) versus $25 \%$ (10 eyes), the overall success rate was $85 \%$ ( 34 eyes) versus $82.5 \%$ ( 33 eyes), and the rate of failure was $15 \%$ ( 6 eyes) versus $17.5 \%$ ( 7 eyes) in NPDS and trabeculectomy groups, respectively (Table 5 and Figure 1). There was no statistically significant difference between the success and failure rates of both groups along different follow-up periods. At 36 months postoperative, there was no statistically significant difference between the 2 groups regarding the success and failure rates $\left(X^{2}=0.098, p=0.952\right)$.

In the NPDS group, half the cases of failure were evident at 3 months postoperative while the other 3 cases were evident by the end of the first year while no further failed cases showed later on. In the trabeculectomy group, three cases of failure were evident at 3 months postoperative while another 3 cases were evident by the end of the first year and a further failed case showed during the second year of follow up.

\section{Postoperative Complications}

Five cases $(12.5 \%)$ versus 7 cases $(17.5 \%)$ of the NPDS and trabeculectomy groups, respectively, had mild

Table 5 The Success and Failure Rates Among the Deep Sclerectomy and Trabeculectomy Groups

\begin{tabular}{|c|c|c|c|c|c|c|}
\hline & \multicolumn{3}{|c|}{ Deep Sclerectomy No. (\%) } & \multicolumn{3}{|c|}{ Trabeculectomy No. (\%) } \\
\hline & Complete Success & Qualified Success & Failure & Complete Success & Qualified Success & Failure \\
\hline I week & $40(100)$ & $0(0)$ & $0(0)$ & $40(100)$ & $0(0)$ & $0(0)$ \\
\hline I month & $38(95)$ & $2(5)$ & $0(0)$ & $40(100)$ & $0(0)$ & $0(0)$ \\
\hline 3 months & $30(75)$ & $7(17.5)$ & $3(7.5)$ & $32(80)$ & $5(12.5)$ & $3(7.5)$ \\
\hline 6 months & $27(67.5)$ & $8(20)$ & $5(12.5)$ & $27(67.5)$ & $8(20)$ & $5(12.5)$ \\
\hline 12 months & $25(62.5)$ & $9(22.5)$ & $6(15)$ & $24(60)$ & $10(25)$ & $6(15)$ \\
\hline 24 months & $25(62.5)$ & $9(22.5)$ & $6(15)$ & $23(57.5)$ & $10(25)$ & $7(17.5)$ \\
\hline 36 months & $24(60)$ & $10(25)$ & $6(15)$ & $23(57.5)$ & $10(25)$ & $7(17.5)$ \\
\hline
\end{tabular}




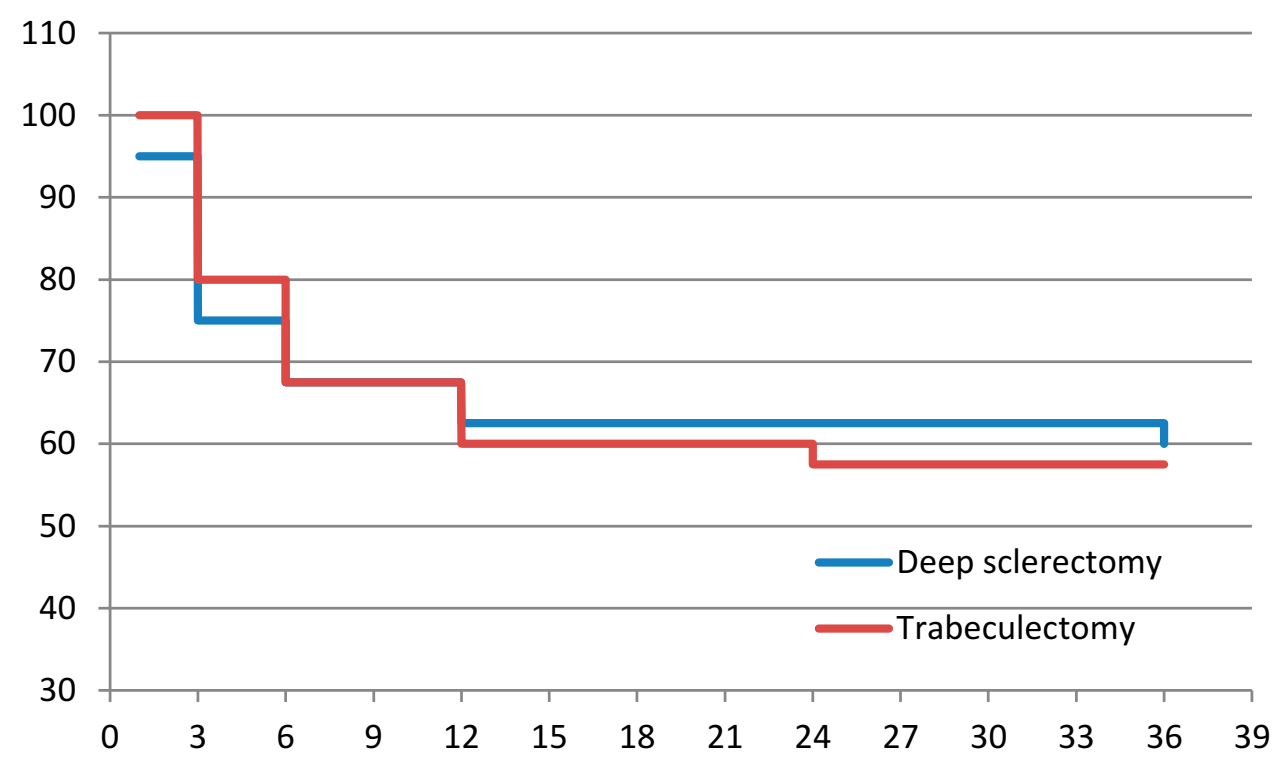

$\mathbf{Y}$ axis: overall success rate (\%), $\mathbf{X}$ axis: time in months

Figure I Survival analysis curve for overall success rates among non-penetrating deep sclerectomy and trabeculectomy groups.

hyphemia which was treated conservatively by topical steroids and mydriatics followed by complete resolution. Two cases $(5 \%)$ of the trabeculectomy group had vitreous loss. One case required revision with anterior vitrectomy and the other required reoperation. None of the cases of both groups had endophthalmitis. Eight cases (20\%) of the trabeculectomy group had shallow anterior chamber; five of them were managed conservatively by mydriatics and withdrawal of steroids while the other three $(7.5 \%)$ had very shallow or lost anterior chamber that required anterior chamber reformation and tight re-suturing of the conjunctival flap. None of the NPDS group cases suffered from shallow anterior chamber. None of the cases of both groups suffered from choroidal detachment or hypotony maculopathy.

The bleb height in trabeculectomy group was well formed in 32, 22, and 17 cases (80\%, 55\%, and 42.5\%), moderately elevated in 7,12 , and 13 cases $(17.5 \%, 30 \%$, and $32.5 \%)$, and flat in 1.6 , and 10 cases $(2.5 \%, 15 \%$, and $25 \%$ ) at 1 month, 6 months, and 36 months, respectively. Bleb thinning was encountered in 3 cases $(7.5 \%)$ of the trabeculectomy group. The bleb vascularization in trabeculectomy group was normal in 28,31 , and 32 cases $(70 \%$, $77.5 \%$, and $80 \%$ ), vascular inflammation in 12,7 , and 2 cases $(30 \%, 17.5 \%$, and $5 \%)$, and avascular in 0,2 , and 6 cases $(0 \%, 5 \%$, and $15 \%)$ at 1 month, 6 months, and 36 months, respectively. There was no conjunctival erosion or matrix extrusion, or allergic reaction to the Ologen material in the NPDS group.

The pupil was rounded in most of the cases of the NPDS group except for 3 cases; two of them showed iris incarceration on gonioscopy and a revision was done which was successful in one case and the other required reoperation, while the third case had a drawn up pupil and required a revision with iris reposition. In the trabeculectomy group, eight cases $(20 \%)$ had either iris incarceration on gonioscopy or showed a drawn up pupil.

Needling or revision was needed in 7 and 13 cases $(17.5 \%$ and $32.5 \%)$ of the NPDS and trabeculectomy groups, respectively. While secondary surgical intervention was needed in 6 and 7 cases (15\% and 17.5\%) of the NPDS and trabeculectomy groups, respectively; this was considered as failure. Ten cases $(15 \%)$ in both groups required topical antiglaucoma medications to decrease the IOP below $16 \mathrm{mmHg}$ in the form of beta-blockers alone (Timolol) or in combination with carbonic anhydrase inhibitor (Dorzolamide); this was considered as qualified success. In other cases, where topical medications were not successful or non-tolerable, they required surgical intervention.

\section{Discussion}

The nature of the treatment of primary congenital glaucoma is mainly surgical. Trabeculotomy or goniotomy is 
needed in the early cases whereas trabeculectomy with or without trabeculotomy is the main surgical procedure in the more advanced cases. However, the complications related to postoperative hypotony and the bleb related complications are among the disadvantages of this procedure. In the current study, the authors investigated the safety and efficacy of non-penetrating deep sclerectomy as a safer alternative to full thickness penetrating trabeculectomy. Non-penetrating deep sclerectomy is at lower risk of experiencing some of the postoperative complications that are encountered with trabeculectomy eg hypotony maculopathy, choroidal detachment, shallow anterior chamber, bleb erosions and vascularization, and bleb infections. This is one of the main advantages of NPDS in avoiding the complications of hypotony. Also, nonpenetrating deep sclerectomy requires less postoperative visits and care of the children. This results from the specificity of the procedure and the different channels of filtration; sub choroidal, intra scleral, and subconjunctival. To our knowledge, there are not so many manuscripts focusing on non-penetrating deep sclerectomy for the treatment of childhood glaucoma.

In the current study, the two groups were almost matched with no significant differences regarding the age and sex of the included patients. The preoperative IOP, corneal diameter, and cup to ratio were also similar. Lack of significant differences between the two groups was a good point to solidify the postoperative results. Both procedures decreased the preoperative IOP levels significantly starting from the first postoperative visit till the end of the 36 months follow up. In the first postoperative week, there were no cases with zero IOP in the NPDS group in contrast to trabeculectomy group. This is one of the main advantages of NPDS avoiding the complications of hypotony. During the first postoperative month, the trabeculectomy significantly decreased the IOP more than NPDS. However, this difference diminished starting from the 3rd month onwards. At the final follow up visit, both procedures were equally effective in controlling the IOP among the included patients.

In the current study, both groups showed comparative success rates whether complete or qualified success. The timing of the failed cases was also comparable between the two groups with nearly half of the failed cases detected in the first three postoperative months. The main advantage of the NPDS group was evident regarding the postoperative period. As mentioned above, none of the NPDS group cases suffered from shallow anterior chamber. So, NPDS patients had enjoyed less stormy postoperative follow-up period.
Al-Obeidan et $\mathrm{al}^{26}$ investigated the safety and efficacy of deep sclerectomy in childhood glaucoma in Saudi Arabia which is another Middle East country near from our country Egypt. The mean follow-up period was 35.8 months. They had complete success rate of $79.7 \%$ and overall success rate of $82.4 \%$. The mean IOP decreased to $11.5 \pm 3.0 \mathrm{mmHg}$ compared to $31.9 \mathrm{mmHg}$ preoperatively. They concluded that NPDS in childhood glaucoma can effectively reduce the IOP without the occurrence of serious complications that are commonly seen after penetrating trabeculectomy. In our series, we had similar follow-up period of 36 months. The complete success rate of our cases was $60 \%$ and the overall success rate was $85 \%$ at 36 months postoperative. This marked difference may be attributed to their cut off level of IOP to consider the success. They defined Complete success rate as achieving an end-point of intraocular pressure $<21 \mathrm{mmHg}$ without any antiglaucoma medications versus our cut off point which was $16 \mathrm{mmHg}$ which is more practical taking into account the lowering IOP effect of inhalational anesthesia. In our series, the mean IOP decreased to $11.2 \pm 4.5 \mathrm{mmHg}$ compared to $27.4 \mathrm{mmHg}$ preoperatively which was comparable to their reported results.

Denis et $\mathrm{al}^{27}$ reported the results of non-penetrating deep sclerectomy with $5 \mathrm{FU}$ in 37 eyes of 28 patients with congenital glaucoma. The mean follow up was 38.2 months. They reported complete success rate of $34 \%$ and overall success rate of $82 \%$ with no severe complications occurring after surgery. Feusier et $\mathrm{al}^{28}$ studied the outcome of combined deep sclerectomy and trabeculectomy with MMC in 35 eyes of 28 patients in cases of childhood glaucoma. The mean follow-up period was 9 years. They reported complete success rate of $52.3 \%$ and overall success rate of $70.6 \%$. They included PCG and secondary childhood glaucoma.

Among the limitations of the study was the relatively small number of cases. There is a need to larger number of cases to further solidify the results. In addition, only primary congenital glaucoma patients were included. There is a need to apply the same method of research to investigate the results in other types of secondary childhood glaucomas. Among the strengths of the study was the good follow up period (36 months), randomization, and the reproducibility of the technique because of operating the surgeries by single experienced surgeon.

In conclusion, non-penetrating deep sclerectomy appears to be an efficient and safe surgical alternative to penetrating trabeculectomy in treatment of primary congenital glaucoma. 
Non-penetrating deep sclerectomy has fewer postoperative complications in comparison to penetrating trabeculectomy with a comparative postoperative reduction in the intraocular pressure and overall success rates.

\section{Data Sharing Statement}

Available upon request from the authors.

\section{Ethics and Approval}

All procedures performed in studies involving human participants were in accordance with the ethical standards of the institutional and/or national research committee and with the 1964 Helsinki declaration and its later amendments or comparable ethical standards. The study was approved by the local ethics committee at the faculty of medicine, Alexandria University, Egypt. Tenets of declaration of Helsinki were followed. The parents or legal caregivers of all the included children signed a written informed consent at the final follow up visit.

\section{Author Contributions}

Both authors contributed to data analysis, drafting or revising the article, gave final approval of the version to be published, and agreed to be accountable for all aspects of the work.

\section{Disclosure}

Both authors declare that they have no conflicts of interest for this work.

\section{References}

1. Aponte EP, Diehl N, Mohney BG. Incidence and clinical characteristics of childhood glaucoma: a population-based study. Arch Ophthalmol. 2010;128(4):478-482. doi:10.1001/archophthalmol.2010.41

2. Mandal AK, Chakrabarti D. Update on congenital glaucoma. Indian J Ophthalmol. 2011;59(Supp11):S148. doi:10.4103/0301-4738.73683

3. Kantipuly A, Pillai MR, Shroff S, et al. Caregiver burden in primary congenital glaucoma. Am J Ophthalmol. 2019;205:106-114. doi:10.1016/j.ajo.2019.05.003

4. Lewis CJ, Hedberg-Buenz A, DeLuca AP, Stone EM, Alward WL, Fingert JH. Primary congenital and developmental glaucomas. Hum Mol Genet. 2017;26(R1):R28-R36. doi:10.1093/hmg/ddx205

5. Shi Y, Wang H, Han Y, et al. Correlation between trabeculodysgenesis assessed by ultrasound biomicroscopy and surgical outcomes in primary congenital glaucoma. Am J Ophthalmol. 2018;196:57-64. doi:10.1016/j.ajo.2018.08.022

6. Shi Y, Wang H, Yin J, et al. Outcomes of microcatheter-assisted trabeculotomy following failed angle surgeries in primary congenital glaucoma. Eye. 2017;31(1):132. doi:10.1038/eye.2016.212

7. Neustein RF, Beck AD. Circumferential trabeculotomy versus conventional angle surgery: comparing long-term surgical success and clinical outcomes in children with primary congenital glaucoma. Am J Ophthalmol. 2017;183:17-24. doi:10.1016/j.ajo.2017.08.008
8. Esfandiari H, Basith SS, Kurup SP, et al. Long-term surgical outcomes of ab externo trabeculotomy in the management of primary congenital glaucoma. J AAPOS. 2019;23(4):222-e1. doi:10.1016/j. jaapos.2019.05.008

9. El Sayed Y, Esmael A, Mettias N, El Sanabary Z, Gawdat G. Factors influencing the outcome of goniotomy and trabeculotomy in primary congenital glaucoma. Br J Ophthalmol. 2019;bjophthalmol-2018.

10. Yeung HH. Failed goniotomy surgery for congenital glaucoma. J Pediatr Ophthalmol Strabismus. 2016;53(3):137. doi:10.3928/ 01913913-20160328-01

11. Sood D, Rathore A, Sood I, Singh G, Sood NN. Long-term outcome of combined trabeculotomy-trabeculectomy by a single surgeon in patients with primary congenital glaucoma. Eye. 2018;32(2):426. doi:10.1038/eye.2017.207

12. Chang TC, Cavuoto KM. Surgical management in primary congenital glaucoma: four debates. J Ophthalmol. 2013;2013:1-7. doi:10.1155/ 2013/612708

13. Reddy BP, Dada T, Sihota R, Panda A, Khokkar SK, Gupta V. Comparative evaluation of trabeculotomy-trabeculectomy with mitomycin c vs trabeculectomy with mitomycin c for primary congenital glaucoma. J Curr Glaucoma Pract. 2011;5(1):15-19. doi:10.5005/jpjournals-10008-1124

14. Razeghinejad MR, Kaffashan S, Nowroozzadeh MH. Results of Ahmed glaucoma valve implantation in primary congenital glaucoma. J AAPOS. 2014;18(6):590-595. doi:10.1016/j.jaapos.2014.08.008

15. Mokbel TH, Khalaf MA, El-Khouly SE, El-Metwally NO. Flexible Ahmed valve for selected cases of refractory glaucoma. Eur J Ophthalmol. 2012;22(1):83-89. doi:10.5301/ejo.5000003

16. Dubey S, Agrawal A, Chauhan L, Mukherjee S, Douglas G. Combined trabeculotomy-trabeculectomy with antimetabolite and releasable suture: outcome with primary congenital glaucoma in a north Indian population. Nepal J Ophthalmol. 2015;7(1):16-25. doi:10.3126/nepjoph.v7i1.13161

17. Bayoumi NH. Deep sclerectomy in pediatric glaucoma filtering surgery. Eye. 2012;26(12):1548. doi:10.1038/eye.2012.215

18. Chen TC, Chen PP, Francis BA, et al. Pediatric glaucoma surgery: a report by the American Academy Of Ophthalmology. Ophthalmology. 2014;121 (11):2107-2115. doi:10.1016/j.ophtha.2014.05.010

19. Sharaawy T, Bhartiya S. Surgical management of glaucoma: evolving paradigms. Indian J Ophthalmol. 2011;59(Supp11):S123. doi:10.41 03/0301-4738.73692

20. Ramtohul P, Chardavoine M, Beylerian M, Aziz A, Matonti F, Denis D. Decompression retinopathy following nonpenetrating deep sclerectomy for primary congenital glaucoma. BMC Ophthalmol. 2018;18(1):240. doi:10.1186/s12886-018-0906-Z

21. Senthil S, Rao HL, Babu JG, Mandal AK, Garudadri CS. Comparison of outcomes of trabeculectomy with mitomycin C vs. ologen implant in primary glaucoma. Indian $J$ Ophthalmol. 2013;61(7):338. doi:10.4103/0301-4738.109520

22. Papaconstantinou D, Georgalas I, Karmiris E, et al. Trabeculectomy with OloGen versus trabeculectomy for the treatment of glaucoma: a pilot study. Acta Ophthalmol (Copenh). 2010;88(1):80-85. doi:10.1111/j.1755-3768.2009.01753.x

23. Perez CI, Mellado F, Jones A, Colvin R. Trabeculectomy combined with collagen matrix implant (Ologen). J Glaucoma. 2017;26 (1):54-58. doi:10.1097/IJG.0000000000000551

24. Van der Walt JG, Roodt F, Tinley C. How does sevoflurane induction, followed by a ketamine maintenance infusion, affect intraocular pressure? Establishment of an anaesthetic protocol for paediatric glaucoma examinations under anaesthesia. $\mathrm{Br} J$ Ophthalmol. 2018;102(7):902-905. doi:10.1136/bjophthalmol-2017-310872

25. Yamada MH, Takazawa T, Iriuchijima N, Horiuchi T, Saito S. Changes in intraocular pressure during surgery in the lateral decubitus position under sevoflurane and propofol anesthesia. $J$ Clin Monit Comput. 2016;30(6):869-874. doi:10.1007/s10877-0159787-3 
26. Al-Obeidan SA, Osman EE, Dewedar AS, Kestelyn P, Mousa A. Efficacy and safety of deep sclerectomy in childhood glaucoma in Saudi Arabia. Acta Ophthalmol (Copenh). 2014;92(1):65-70. doi:10.1111/j.17553768.2012.02558.x

27. Denis D, Pommier S, Coste R, et al. Deep sclerectomy in congenital glaucoma: results of a study lasting more than 3 years. $J \mathrm{Fr}$ Ophthalmol. 2008;31:173-179. doi:10.1016/S0181-5512(08)70350-4
28. Feusier M, Roy S, Mermoud A. Deep sclerectomy combined with trabeculectomy in pediatric glaucoma. Ophthalmology. 2009;116 (1):30-38. doi:10.1016/j.ophtha.2008.08.039
Clinical Ophthalmology

\section{Publish your work in this journal}

Clinical Ophthalmology is an international, peer-reviewed journal covering all subspecialties within ophthalmology. Key topics include: Optometry; Visual science; Pharmacology and drug therapy in eye diseases; Basic Sciences; Primary and Secondary eye care; Patient Safety and Quality of Care Improvements. This journal is indexed on PubMed

Submit your manuscript here: https://www.dovepress.com/clinical-ophthalmology-journal
Dovepress

Central and CAS, and is the official journal of The Society of Clinical Ophthalmology (SCO). The manuscript management system is completely online and includes a very quick and fair peer-review system, which is all easy to use. Visit http://www.dovepress.com/ testimonials.php to read real quotes from published authors. 